\title{
Modification of Nafion Membranes by IL-Cation Exchange: Chemical Surface, Electrical and Interfacial Study
}

\author{
V. Romero, ${ }^{1}$ M. V. Martínez de Yuso, ${ }^{2}$ A. Arango, ${ }^{2}$ E. Rodríguez-Castellón, ${ }^{2}$ and J. Benavente ${ }^{1}$ \\ ${ }^{1}$ Departamento de Física Aplicada I, Facultad de Ciencias, Universidad de Málaga, 29071 Málaga, Spain \\ ${ }^{2}$ Departamento de Química Inorgánica, Facultad de Ciencias, Universidad de Málaga, 29071 Málaga, Spain \\ Correspondence should be addressed to J. Benavente, j_benavente@uma.es
}

Received 4 September 2011; Revised 19 December 2011; Accepted 2 January 2012

Academic Editor: Oliver Höfft

Copyright ( 2012 V. Romero et al. This is an open access article distributed under the Creative Commons Attribution License, which permits unrestricted use, distribution, and reproduction in any medium, provided the original work is properly cited.

\begin{abstract}
Bulk and surface changes in two proton-exchange membranes (Nafion-112 and Nafion-117) as a result of the incorporation of the IL-cation $n$-dodecyltriethylammonium $\left(\right.$ or $\mathrm{DTA}^{+}$) by a proton/cation exchange mechanism after immersion in a DTA ${ }^{+}$aqueous solution were analysed by impedance spectroscopy (IS), differential scanning calorimetry (DSC), X-ray photoelectron spectroscopy (XPS), and contact angle measurements performed with dry samples of the original Nafion and Nafion-DTA ${ }^{+}$-modified membranes. Only slight differences were obtained in the incorporation degree and surface chemical nature depending on the membrane thickness, and $\mathrm{DTA}^{+}$incorporation modified both the hydrophobic character of the original Nafion membranes and their thermal stability. Electrical characterization of the dry Nafion-112 membrane was performed by impedance spectroscopy while different $\mathrm{HCl}$ solutions were used for membrane potential measurements. A study of time evolution of the impedance curves measured in the system "IL aqueous solution/Nafion-112 membrane/IL aqueous solution" was also performed. This study allows us monitoring the electrical changes associated to the IL-cation incorporation in both the membrane and the membrane/IL solution interface, and it provides supplementary information on the characteristic of the Nafion/DTA ${ }^{+}$hybrid material. Moreover, the results also show the significant effect of water on the electrical resistance of the Nafion-112/IL-cation-modified membrane.
\end{abstract}

\section{Introduction}

As it is well known, ionic liquids are room temperature molten salts (RTILs) with very low vapour pressure and composed only of ions. These salts are characterized by weak interactions owing to the combination of a large cation and a charge-delocalized anion. Ionic liquids exhibit very interesting properties such as the solubilization of a large range of organic molecules and transition metal complexes or the possibility of their repeated use due to reduced environmental loss, while their good thermal stability tolerates reactive processes at high temperatures favouring a faster kinetic [14]. Various kinds of salts can be used to design an ionic liquid with tailoring properties for a given application, but typical IL-cations are imidazolium and quaternary ammonium salts, while hexafluorophosphate is a common anion. Due to their particular characteristics, the use of ILs in many areas of technology and science has increased lately and they can be used as solvents for organic reactions and catalysis, $\mathrm{CO}_{2}$ capture devices, selective separation of chemical species, dissolution of natural biomaterials, energy conversion, bioscience, and so forth [5-7]. Miscibility of ionic liquids with water is also a point of interest and it seems to be mostly determined by the associated anion. RTILs with anions such as halides, $\mathrm{BF}_{4}{ }^{-}$, nitrate, and perchlorate, are water miscible, while those with $\mathrm{PF}_{6}{ }^{-} \mathrm{AsF}_{6}{ }^{-}$, and so forth are immiscible. The activity of water seems to be higher in the hydrophobic ionic liquid than in the hydrophilic one and thus water will partition to the gas-liquid interface of the immiscible ionic liquid more than in the miscible one [8].

The conductivity of ionic liquids is also being studied for their application in batteries and fuel cells. As it is well known a fuel cell basically consists of two electrodes sandwiching a proton-conducting membrane (or MEA). Nafion is the polymeric material widely used as a reference in proton fuel cell (PEMFCs) due to its high ionic conductivity as well as its 
mechanical and chemical stability at room temperature, and it consists of a backbone of polytetrafluoroethylene (PTFE) with sidechains of perfluorovinylether (PFAE) with a sulfonic group end. Nafion combines the high hydrophobicity of the PTFE with the great hydrophilicity of the sulfonic groups at intervals along the chain, which facilitate the transport of ions and give it the character of a polymer electrolyte structure $[9,10]$. The mechanism of transport across the Nafion membranes seems to be associated to both the presence of water and its state within the membrane structure $[11,12]$, which is a point of significant importance for its application in PEMFCs due to the conductivity decrease found in Nafion membranes at temperature above $80^{\circ} \mathrm{C}$, which is associated to the Nafion membrane water loss. For this reason some authors have proposed the modification of Nafion membranes by incorporation of ILs as a way to reduce the Nafion limitation at temperature higher than $120^{\circ} \mathrm{C}$ as a result of water loss and/or to minimize other kinds of electrode/membrane surface interactions due to electrode or catalyst changes [13-16].

In this context, it should be pointed out the significant number of papers published in recent years dealing with original and modified proton-exchange membranes conductivity and permeability, which are considered key parameters for their applications in proton and methanol (DMFCs) fuel cells, respectively [16-22]; particularly, a reduction of around two orders of magnitude in the methanol permeability across Nafion/IL-modified membranes attributed to the decrease of the methanol crossover associated to the presence of the ILcation has already been reported [23]. However, a more reduced number of papers on surface study of both original and modified membranes are published, although membrane surface represents the interface between two different transport media, which can be solid/solid in the case of fuel cells or solid/liquid when supported liquid membranes (SLMs) or other electrochemical devices proposed for selective solute separation are considered $[15,24,25]$.

This work studies both surface and bulk phase changes caused in two polytetrafluoroethylene sulfonate Nafion membranes (both in protonated form but different thickness) as a result of the incorporation of a IL-cation ( $n$-dodecyltriethylammonium or $\mathrm{DTA}^{+}$) by cation-exchange mechanism after their immersion in a water $\mathrm{DTA}^{+}$(Nafion/ $\mathrm{DTA}^{+}$samples). Surface changes associated to IL-cation incorporation in the Nafion membranes were studied by X-ray photoelectron spectroscopy (XPS) analysis and contact angle measurements, while its effect on the thermal stability of the Nafion membranes was determined by analyzing the DSC curves. Electrical modifications in dry Nafion/IL-cation samples were determined by impedance spectroscopy (IS) measurements, but proton transport numbers across the membrane were obtained from membrane potential measurements carried out with the membranes in contact with $\mathrm{HCl}$ aqueous solutions. Moreover, IS technique was also used for the electrical characterization of the IL solution/Nafion 112 membrane/IL solution system, which was performed at different times $(0 \leq t(h) \leq 40)$ as a way of monitoring kinetic changes in the membrane and the membrane/IL-solution interface and to estimate of interfacial effects.

\section{Experimental}

2.1. Materials. A protonated Nafion membrane from Dupont (USA), Nafion-112, was modified by incorporation of the IL-cation n-dodecyltrimethylammonium $\left(\mathrm{DTA}^{+}\right)$ through $\mathrm{H}^{+}$/cation exchange mechanism [15]. The membrane has the following characteristics given by the manufacturer: nominal thickness of $51 \mu \mathrm{m}$, density $2000 \mathrm{~kg} / \mathrm{m}^{3}$, ionic conductivity $8.3 \mathrm{~S} / \mathrm{m}$, acid capacity $0.89 \mathrm{meq} / \mathrm{g}$, and initial water content $5 \mathrm{wt} \%$. To see the effect of membrane thickness on the IL-cation incorporation degree and membrane surface characteristics another similar membrane with a thickness of $180 \mu \mathrm{m}$ (Nafion-117 sample) was also studied. The DTA $^{+}\left(\mathrm{C}_{12} \mathrm{H}_{25} \mathrm{~N}\left(\mathrm{CH}_{3}\right)_{3}{ }^{+}\right)$IL-cation characteristics are molecular weight of $228 \mathrm{~g} / \mathrm{mol}$ and molar volume (estimated by Schroeder' method [26]) of $350 \mathrm{~cm}^{3} / \mathrm{mol}$ and it was supplied by TCI Instrument (England). Although $\mathrm{DTA}^{+} \mathrm{Cl}^{-}$is not an ionic liquid but a quaternary amine, the $\mathrm{DTA}^{+}$cation is typical of common ILs.

Samples of Nafion-112 and Nafion-117 membranes without any previous pretreatment were immersed in a $60 \%$ $\mathrm{DTA}^{+} \mathrm{Cl}^{-}$aqueous solution and variations in the liquid of $\mathrm{pH}$ and conductivity were measured using a $\mathrm{pH}$ conductivity meter (model $720 \mathrm{~A}$, Orion) and a conductivity meter (model 960, Schott Instruments), respectively. Both the $\mathrm{pH}$ and the conductivity were measured before and after $\mathrm{DTA}^{+}$incorporation to determine the concentration of ions inside the membranes. The incorporation degree, ID $\left(\mathrm{mol} / \mathrm{m}^{3}\right)$, was determined by the following expression: ID $=\left(K_{t}-K_{0}\right) / \lambda_{\mathrm{H}}{ }^{+}$, where $K_{0}$ and $K_{t}$ represent the conductivity of the IL-aqueous solution at times 0 and $t$, respectively, while $\lambda_{\mathrm{H}}{ }^{+}$is the proton conductivity; taking into account the solution volume and the ion-exchange capacity of a given membrane the percentage of cation incorporation ( $\mathrm{mol} / \mathrm{membrane}$ mass) was determined. All these measurements were performed at the laboratory of Professor J. Crespo, REQUIMTE/CQFB, FCT, Universidade Nova de Lisboa (Portugal).

2.2. XPS Measurements. The chemical characterisation of the surface of the studied modified membranes and the Nafion-112 was performed by XPS. A Physical electronics spectrometer (PHI 5700) was used, with X-ray $\mathrm{Mg} \mathrm{K} \alpha$ radiation $(300 \mathrm{~W}, 15 \mathrm{kV}, 1253.6 \mathrm{eV})$ as the excitation source. High-resolution spectra were recorded at a given take-off angle of $45^{\circ}$ by a concentric hemispherical analyser operating in the constant pass energy mode at $29.35 \mathrm{eV}$, using a $720 \mu \mathrm{m}$ diameter analysis area. Under these conditions, the Au $4 f_{7 / 2}$ line was recorded with $1.16 \mathrm{eV} \mathrm{FWHM}$ at a binding energy of $84.0 \mathrm{eV}$. The spectrometer energy scale was calibrated using $\mathrm{Cu} 2 p_{3 / 2}, \mathrm{Ag} 3 d_{5 / 2}$, and $\mathrm{Au} 4 f_{7 / 2}$ photoelectron lines at 932.7, 368.3, and $84.0 \mathrm{eV}$, respectively. Charge referencing was done against $-\mathrm{CF}_{2}$-carbon of Nafion (C $\left.1 s, 292.0 \mathrm{eV}\right)$.

Membranes were mounted on a sample holder without adhesive tape and kept overnight at high vacuum in the preparation chamber before being transferred to the analysis chamber of the spectrometer for testing. Each spectral region was scanned for several sweeps until a good signal-to-noise ratio was observed. The pressure in the analysis chamber was maintained lower than $5 \times 10^{-6} \mathrm{~Pa}$. PHI ACCESS 
ESCA-V6.0 F software package was used for acquisition and data analysis. A Shirley-type background was subtracted from the signals. Recorded spectra were always fitted using Gauss-Lorentz curves and following the methodology described in detail elsewhere [24], in order to determinate more accurately the binding energy (BE) of the different element core levels. Atomic concentration percentages of the characteristic elements of the surfaces were determined taking into account the corresponding area sensitivity factor [25] for the different measured spectral regions. Membrane samples were irradiated for a maximum time of $20 \mathrm{~min}$ to minimize possible X-ray damage.

2.3. Contact Angle Measurements. The hydrophobic/hydrophilic character of the membrane surfaces was determined from contact angles measurements, and they were performed with a Teclis T2010 instrument equipped with a video system. Membrane samples were mounted on glass slides to provide a flat surface for analysis. The drop method was used to measure the contact angle of deionized water on the surface of the membranes at ambient temperature. Dry samples of Nafion-112, Nafion-117, Naf-112/DTA ${ }^{+}$, and Naf$117 / \mathrm{DTA}^{+}$membranes with any pretreatment were analyzed.

2.4. Thermal Analysis. TG/DSC analysis was performed with a thermobalance TGA/DSC1 of Mettler. A working air flow of $50 \mathrm{~cm}^{3} / \mathrm{min}$ was used for measurements carried out under most similar atmospheric conditions. The TG profile was collected in the $30<T\left({ }^{\circ} \mathrm{C}\right)<750$ temperature range with a heating rate of $10^{\circ} \mathrm{C} / \mathrm{min}$, using an open platinum pan of $70 \mu \mathrm{L}$. The thermal analysis was performed with dry samples of all the membranes with any pretreatment.

\subsection{Impedance Spectroscopy and Membrane Potential Mea-} surements. Impedance spectroscopy (IS) measurements with dry Naf-112/DTA ${ }^{+}$and Naf-117/DTA ${ }^{+}$samples at equilibrium IL-cation incorporation were performed in a cell consisting of a Teflon support on which two Pt electrodes were placed and screwed down [27]. However, an electrochemical cell similar to that described in [28], which consists in two glass half cells with the membranes placed in the middle and separating the IL-solutions was used for IS measurements with both the IL-solution and the IL-solution/membrane/ILsolution. Time evolution of the impedance curves measured in this latter system allows the monitoring of dynamical changes in both the membrane bulk phase and the membrane/IL-solution interface.

With both cell systems, IS measurements were performed using a response frequency analyzer (Solartron 1260, England) controlled by a computer. 100 different frequencies in the range $1 \mathrm{~Hz}-10^{7} \mathrm{~Hz}$ at a maximum voltage of $0.01 \mathrm{~V}$ were measured, and the experimental data were corrected by software, the influence of connecting cables, and other parasite capacitances.

The electromotive force, $\Delta E$, between two $\mathrm{HCl}$ solutions of concentrations $c_{1}$ and $c_{2}$ at both sides of the membranes caused by the concentration gradient was measured by two reversible $\mathrm{Ag} / \mathrm{AgCl}$ electrodes connected to a digital

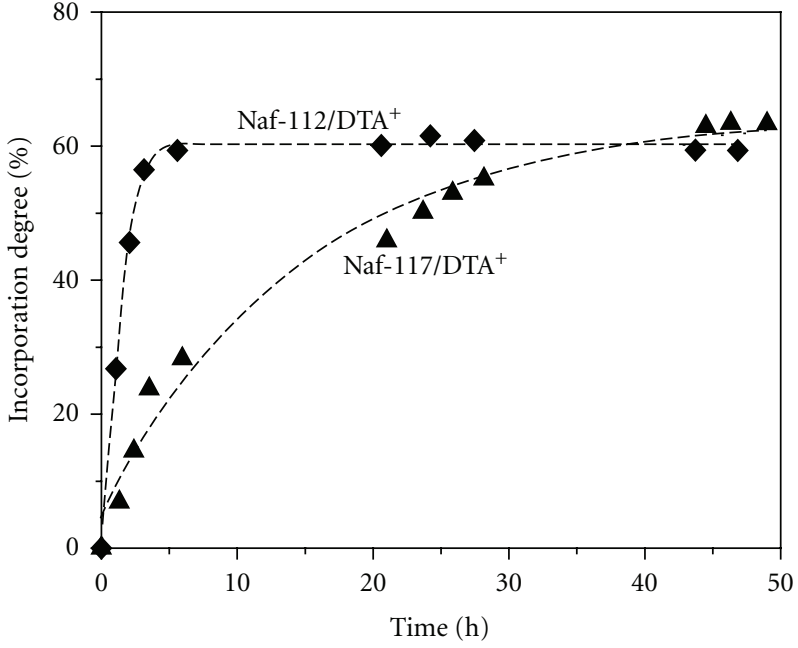

Figure 1: Time dependence of $\mathrm{DTA}^{+}$incorporation into the structure of $(\diamond)$ Nafion-112 membrane and ( $\mathbf{\Delta})$ Nafion-117 membrane.

voltmeter (Yokohama 7552, $1 \mathrm{G} \Omega$ input resistance). Measurements were carried out by keeping the concentration of the solution at one membrane side constant $\left(c_{1}=0.001 \mathrm{M}\right)$ and gradually changing the concentration of the solution at the other side, $c_{2}$, from $2 \times 10^{-4} \mathrm{M}$ to $7.5 \times 10^{-3} \mathrm{M}$ [27].

\section{Results and Discussion}

3.1. Incorporation of $\mathrm{DTA}^{+}$Cation in the Nafion Membranes. The dynamic of IL-cation inclusion into Nafion-112 and Nafion-117 membranes as a function of the contact time is shown in Figure 1, where the incorporation degree is expressed as a \% of the cationic exchange capacity of Nafion samples. Differences in the kinetic of $\mathrm{DTA}^{+}$incorporation depending on the thickness of the Nafion membrane thickness were obtained, which seems to be related to the time necessary to reach an equilibrium state (around $5 \mathrm{~h}$ for Nafion112 and $30 \mathrm{~h}$ for Nafion-117), while the equilibrium value for $\mathrm{DTA}^{+}$incorporation hardly depends on the membrane (59.6\% for Naf-112/DTA ${ }^{+}$and $61.4 \%$ for Naf-117/DTA ${ }^{+}$), which allows the estimation of an average value of (60.5 \pm $0.5) \%$ for Nafion-DTA ${ }^{+}$aqueous solution system.

3.2. Membrane Surface Characterization. Surface chemical changes associated to the inclusion of the IL-cation $\mathrm{DTA}^{+}$ into the structure of the Nafion membranes was studied by XPS analysis, which allows the determination of the atomic concentration percentage (A.C. \%) of the elements present on the surfaces of both Nafion and Nafion/ILmodified membranes, which were obtained from high resolution spectra of the main photoelectron peaks (C $1 s, \mathrm{O} 1 s, \mathrm{~F} 1 s, \mathrm{~S} 2 p$, and $\mathrm{N} 1 s)$. Figure 2 shows the chemical structure of Nafion, while Table 2 presents the atomic concentration percentages (A.C.) of the characteristic elements found on the surface of the Nafion-112 and Nafion-117 membranes and the Nafion/IL-cation modified samples at equilibrium state, that is, after more than $40 \mathrm{~h}$ in contact with the IL-cation aqueous solution; small 


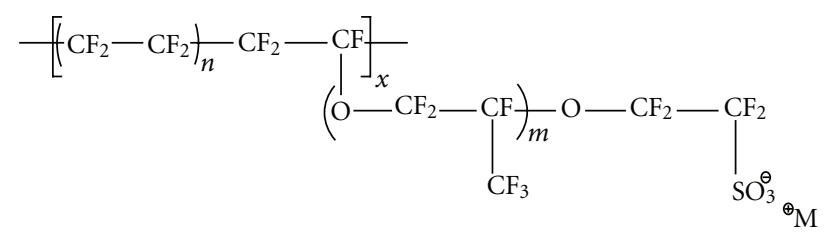

Figure 2: Chemical structure of Nafion.

TABle 1: Atomic concentration percentages of the characteristic elements found on the membranes surfaces.

\begin{tabular}{lccccc}
\hline Sample & C\% & O\% & F\% & S\% & N\% \\
\hline Nafion (theoretical) & 30.8 & 7.7 & 60.0 & 1.5 & - \\
Naf-112 & 39.0 & 6.6 & 53.4 & 1.0 & 0.2 \\
Naf-117 & 41.4 & 6.4 & 50.5 & 0.9 & 0.4 \\
Naf-112/DTA & 54.5 & 11.5 & 27.2 & 1.1 & 2.8 \\
Naf-117/DTA $^{+}$ & 49.5 & 9.8 & 36.2 & 1.1 & 1.5 \\
\hline
\end{tabular}

TABLE 2: Average values of the contact angles for original and ILmodified membranes.

\begin{tabular}{lc}
\hline Membrane & Average contact angle $\left(^{\circ}\right)$ \\
\hline Nafion-112 & $91 \pm 2$ \\
Nafion-117 & $91 \pm 3$ \\
Naf-112/DTA & \\
Naf-117/DTA &
\end{tabular}

percentages $<0.5 \%$ of other elements such as chlorine and silicon were also found and they are associated to surface contamination. For comparison, the theoretical values for the Nafion membrane calculated by its chemical formulae are also indicated in Table 2, and only slight differences between theoretical and experimental values for both Nafion membranes were obtained, which could be due to membranes surfaces contamination, particularly to the presence of adventitious carbon [29].

As can be observed in Table 1 , the concentration of fluorine (Nafion characteristic element) in both modified membranes is significantly lower than in the original samples due to the membrane surface coverage by the IL; however, high experimental carbon percentage was obtained for both modified samples, which could be associated to $\mathrm{DTA}^{+}$component, but the result of surface contamination indicated above might affect the A.C. of this element.

This point can be discriminated by considering the XPS spectra, which give information on the chemical interactions among the different elements on the solid surface. Figure 3 shows the $\mathrm{C} 1 \mathrm{~s}$ core level spectrum for Nafion-112 and both Nafion/IL-cation modified membranes (Naf-112/DTA ${ }^{+}$and Naf-117/DTA ${ }^{+}$and certain differences can be observed. The Nafion-112 sample shows three different photoemissions at binding energies (BE) of $291.8-292.0 \mathrm{eV}$ (associated to $\mathrm{CF}_{2}$ and $\mathrm{CF}-\mathrm{O}$ ) and at $284.8-285.0 \mathrm{eV}(\mathrm{C}-\mathrm{H}$ bond), plus a small shoulder at $294.0 \mathrm{eV}\left(\mathrm{CF}_{3}\right)$. The $\mathrm{C} 1 \mathrm{~s}$ spectra for both Nafion/ $\mathrm{DTA}^{+}$-modified membranes also present those peaks and shoulder, but another shoulder at $286.4 \mathrm{eV}$ associated to $\mathrm{C}-\mathrm{N}$ can also be observed $[29,30]$.

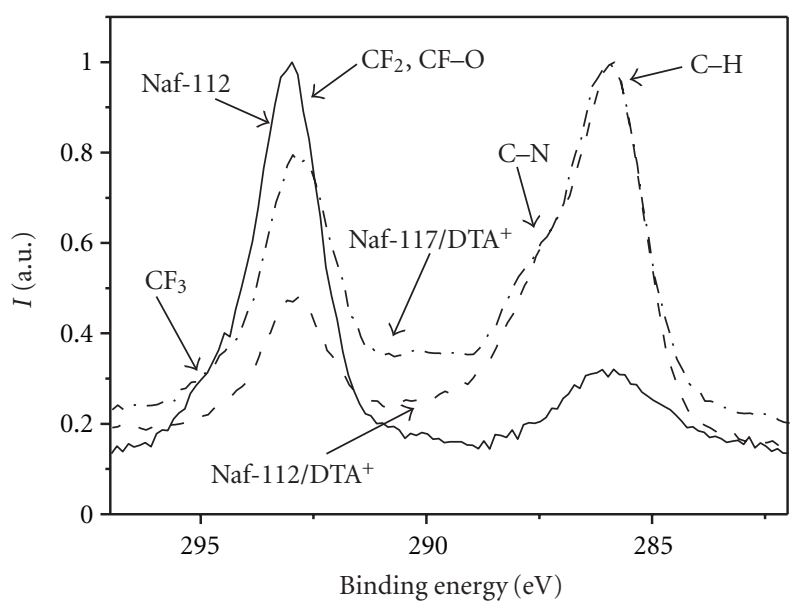

Figure 3: Comparison of the $C$ 1s core level spectra obtained for Nafion-112, Naf-112/DTA ${ }^{+}$, and Naf-117/DTA ${ }^{+}$, membranes (both modified membranes after $48 \mathrm{~h}$ in contact with the IL-solution).

Surface modification of the Nafion membranes associated to the incorporation of the IL-cation might also affect its hydrophobic character, which can be determined by contact angle measurements. Figure 4 shows differences in the form of the water drops on the surface of the Nafion-112 membrane and the Naf-112/DTA ${ }^{+}$sample after $40 \mathrm{~h}$ of immersion in the solution, which is a clear indication of the superficial changes due to $\mathrm{DTA}^{+}$incorporation. Table 2 shows the average contact angle values obtained for the studied membranes; as can be observed practically the same values were obtained for original Nafion-112 and Nafion117 membranes, but small differences were found between both IL-cation-modified samples presenting membrane Naf$112 / \mathrm{DTA}^{+}$a slightly more hydrophilic character, which also agrees with XPS results.

Since the results presented in this section only show slight chemical surface differences for both Nafion-IL-modified membranes related to the sample thickness, in the following section dedicated to the electrical effect of IL-cation modification only the Naf-112/DTA ${ }^{+}$membrane will be considered.

3.3. Thermal Characterization of Original and IL-CationModified Membranes. The thermogravimetric profiles of the Nafion-112 and Nafion-117 pristine membranes show a weight loss of $79.76 \%$ between 320 and $4700^{\circ} \mathrm{C}$ (for Nafion117 ) and $72.8 \%$ between 310 and $480^{\circ} \mathrm{C}$ (for Nafion-112). The profile obtained for the Nafion-117 sample is similar to that observed by Di Noto et al. [31], although measurements were performed under different conditions $\left(\mathrm{N}_{2}\right.$ atmosphere in [31] and in air in this paper). Upon incorporation of $\mathrm{DTA}^{+}$, the weight losses occur at higher temperatures: $85.8 \%$ between 340 and $520^{\circ} \mathrm{C}$ for Nafion-117/DTA ${ }^{+}$and $77.8 \%$ between 350 and $550^{\circ} \mathrm{C}$ for Nafion-112/DTA ${ }^{+}$, which also includes the degradation of the $\mathrm{DTA}^{+}$. According to DSC results the incorporation of $\mathrm{DTA}^{+}$seems to communicate higher thermal stability to the studied membranes, which is reflected by the higher finishing decomposition temperatures 


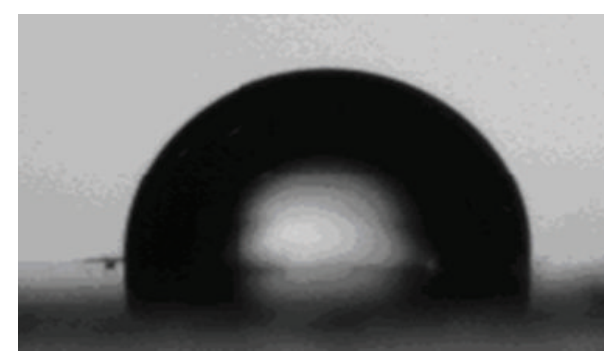

(a)

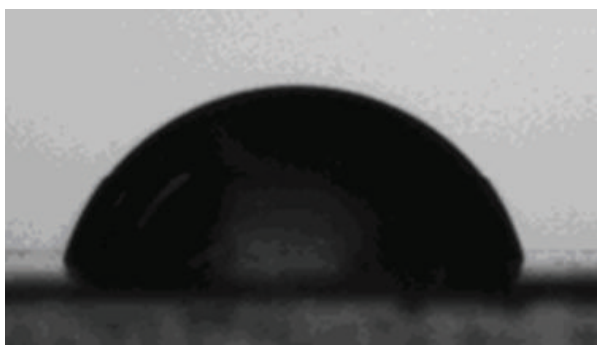

(b)

FIGURE 4: Differences in the hydrophobic character of (a) Nafion112 and (b) Naf-112/DTA ${ }^{+}$membranes by the comparison of watermembrane surfaces contact angles.

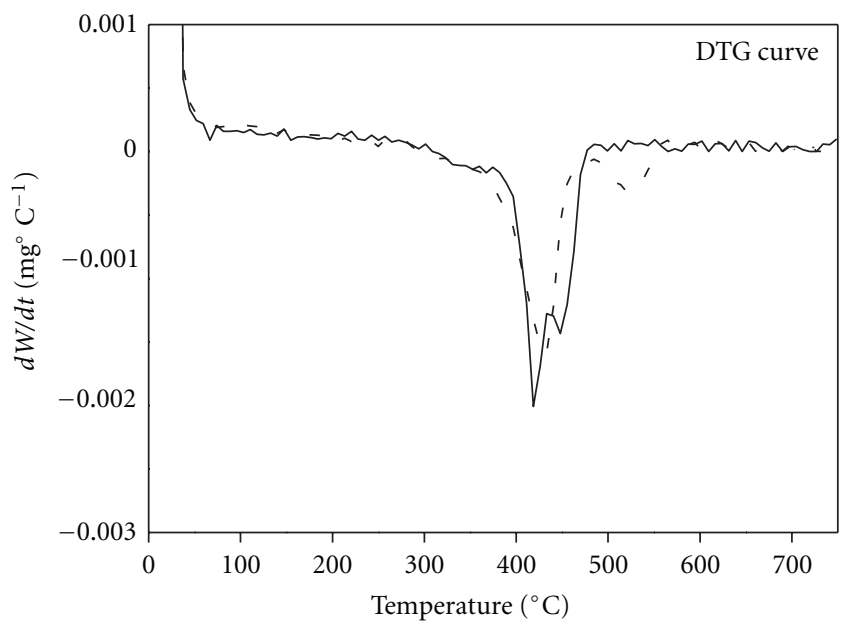

FIGURE 5: DTG profiles for Nafion-117 (solid line) and Nafion-117/ $\mathrm{DTA}^{+}$(dashed line) membranes.

for membranes containing DTA. The DTG profiles also confirm this point as can be observed in Figure 5, where a comparison between Nafion-117 and Nafion-117/DTA ${ }^{+}$membranes is presented. The minima of the DTG curve for Nafion-117/DTA ${ }^{+}$membrane are shifted to higher temperatures in comparison to those observed in the DTG curve for the pristine Nafion-117.

3.4. Electrical Characterization of the Naf-112/DTA ${ }^{+} \mathrm{Mem}-$ brane. The evaluation of the electric modification of Nafion112 membrane by IL-cation incorporation was performed by

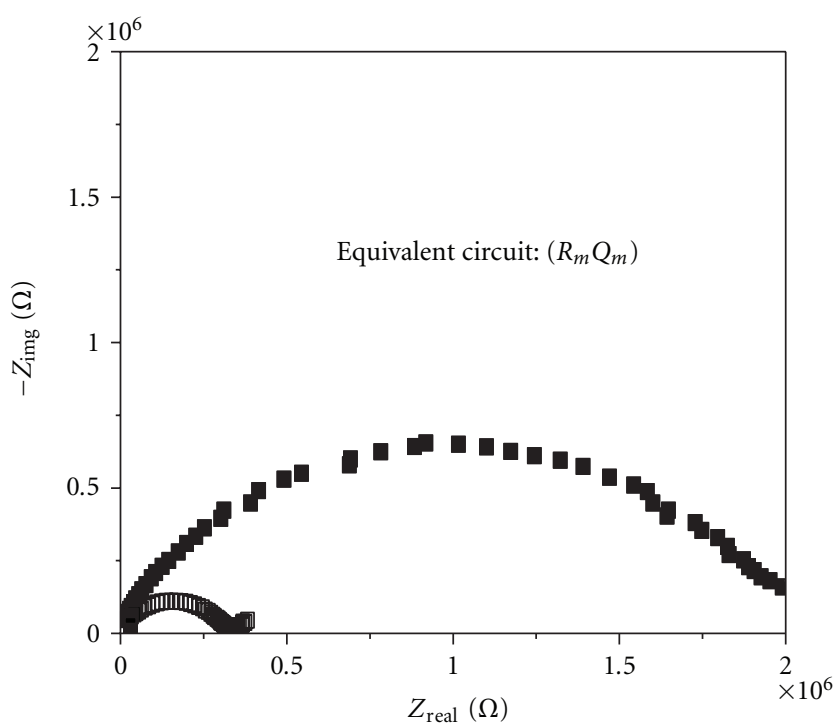

FIGURE 6: Nyquist plot ( $-Z_{\text {img }}$ versus $\left.Z_{\text {real }}\right)$ and equivalent circuit for Naf-112/DTA ${ }^{+}$dry sample ( $)$and Naf-112/DTA ${ }^{+}(w)$ hydrated sample $(\square)$, that means, after $24 \mathrm{~h}$ submerged in distilled water.

impedance spectroscopy and membrane potential measurements. Since these latter measurements are carried with $\mathrm{HCl}-$ aqueous solutions, the effect of water on membrane electrical parameters is also considered by comparing impedance curves for $\mathrm{Naf}-112 / \mathrm{DTA}^{+}$and after $24 \mathrm{~h}$ submerged in distilled water $\left(\mathrm{Naf}-112 / \mathrm{DTA}^{+}(\mathrm{w})\right)$ samples. Figure 6 shows a comparison of the Nyquist $\left(-Z_{\text {imag }}\right.$ versus $\left.Z_{\text {real }}\right)$ plot obtained for both samples, where significant differences can be observed, although in both cases the equivalent circuit corresponds to a parallel association of a resistance $\left(R_{m}\right)$ and a constant phase element $\left(Q_{m}\right)$ or nonideal capacitor [32, $33]$. The fitting of the impedance date by a nonlinear program allows the estimation of $R_{m}$ [34] and the following values were obtained: $R_{m}\left(\mathrm{Naf}-112 / \mathrm{DTA}^{+}\right)=2 \times 10^{6} \mathrm{ohm}$ and $R_{m}\left(\mathrm{Naf}-112 / \mathrm{DTA}^{+}(\mathrm{w})\right)=2.8 \times 10^{5} \mathrm{ohm}$, this represents practically one order of magnitude lower for the hydrated membrane. However, no indication of membrane conductivity $(\sigma)$ can be determined from these results since the well-known and commonly used relationship between electrical resistance and conductivity, $R=L / \sigma \cdot S$, is only valid for homogeneous conductors, and it is not applicable to the modified membranes since no evidence of homogeneous distribution of the IL-cation throughout the Nafion structure exists. In any case, the obtained values show the significant increase of electrical resistance caused in the Nafion membrane by the inclusion of the IL-cation but membrane rehydration clearly reduce this effect.

This point can be more clearly observed in Figures 7 (a) and 7 (b) where a comparison of the Bode diagrams $\left(Z_{\text {real }}\right.$ versus frequency and $-Z_{\text {imag }}$ versus frequency, resp.) for Nafion-112, Naf-112/DTA ${ }^{+}$, and Naf-112/DTA ${ }^{+}(\mathrm{w})$ samples is presented. As can be observed, significantly lower values for the real part of the impedance (directly related to electrical resistance) were obtained for the original Nafion-

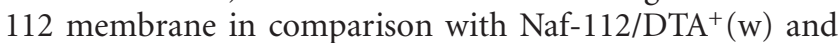




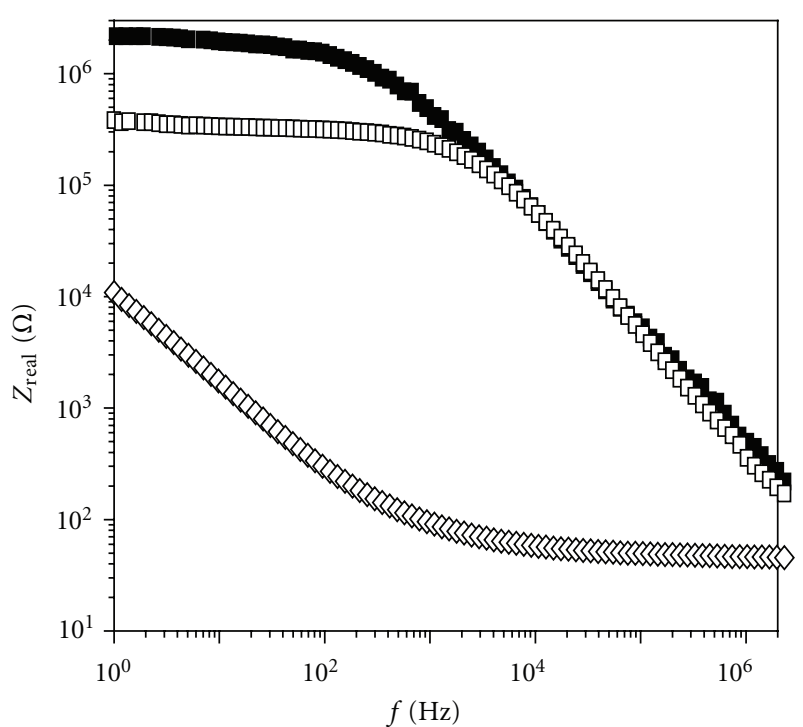

(a)

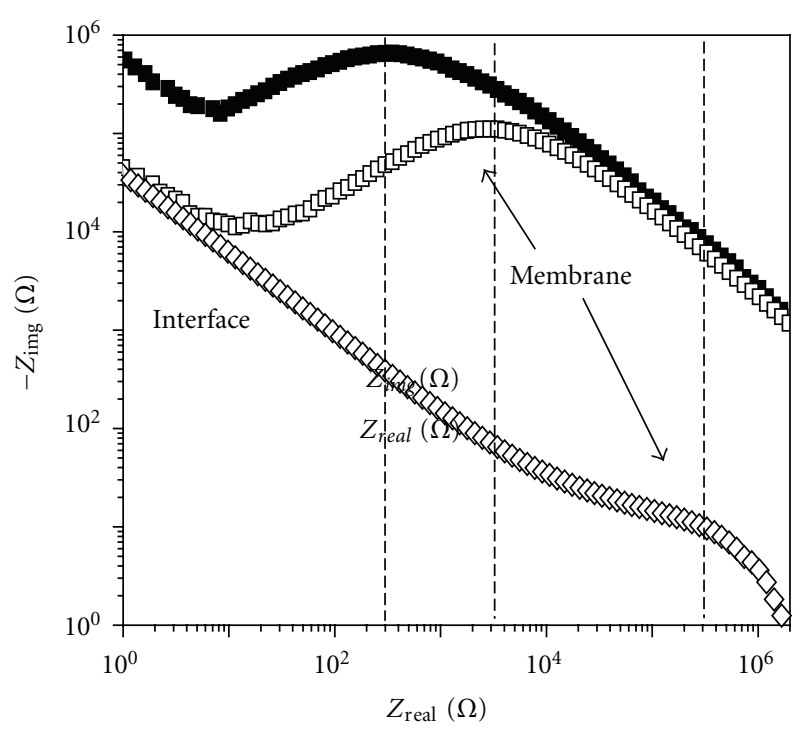

(b)

Figure 7: Bode plots, (a) $Z_{\text {real }}$ versus frequency and (b) $Z_{\text {img }}$ versus frequency, for Nafion-112 ( $\left.\diamond\right)$, Naf-112/DTA ${ }^{+}$dry $(\mathbf{\square})$ and Naf-112/ $\operatorname{DTA}^{+}(\mathrm{w})(\square)$ membranes.

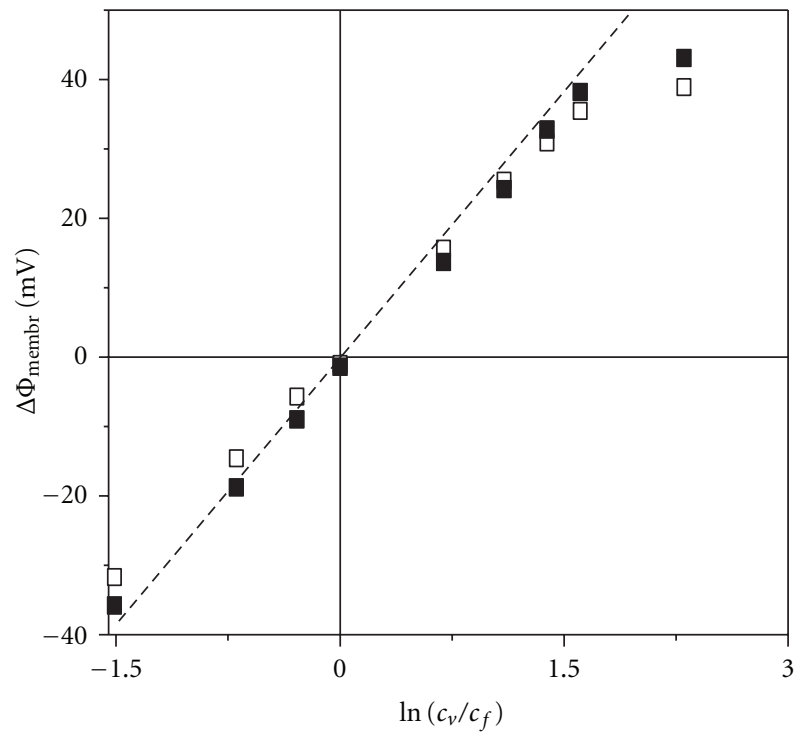

Figure 8: Membrane potentials versus solution concentrations ratio for Nafion-112 ( $\square)$ and Naf-112/DTA ${ }^{+}(\mathbf{\square})$ in contact with $\mathrm{HCl}$ solutions.

Naf-112/DTA ${ }^{+}$samples ( 3 or 4 orders of magnitude, resp.), while the shift to lower values of the maximum relaxation frequency obtained for the IL-modified samples might be related to a more compact charge packing.

Membrane potential, $\Delta \Phi_{\text {memb }}$, is the electrical potential difference between both sides of a membrane separating two solutions of the same electrolyte but different concentrations $\left(c_{1}\right.$ and $c_{2}$ ) [35]. Figure 8 shows the variation of membrane potentials with the logarithm of the solution concentrations ratio, where a practically linear relationship can be observed; for comparison, membrane potential for an ideal cationexchange membrane is also shown in Figure 7 (dotted line) and these values hardly differ from those corresponding to both Naf-112/DTA ${ }^{+}$and Nafion-112 membranes in agreement with the well-known electronegative character of this sample.

Ion transport number $\left(t_{i}\right)$ is the parameter commonly used to characterize the effect of membrane charge on the transport of ions since it represents the fraction of the electric current transported by an ion $i\left(t_{i}=I_{i} / I_{\mathrm{T}}\right.$, then $\sum_{i} t_{i}=1$; $t_{+}+t_{-}=1$ for single salts). For an ideal cation-exchanger membrane $t_{+}=1$, and the $\Delta E$ for the concentration cell reaches the maximum value [35]: $\Delta E_{\max }=-(2 R T /$ F) $\ln (c 2 / c 1)$; then, the value of the cation transport number for two given concentrations ( $c 1$ and $c 2$ ) can be obtained as: $t_{+}=\Delta E / \Delta E_{\max }$. Cation transport numbers across Nafion112 and Naf-112/DTA ${ }^{+}$membranes were calculated and the following average values were obtained: $\left\langle t_{+}(\right.$Nafion-112) $\rangle=$ $(0.946 \pm 0.006)$ and $\left\langle t_{+}\left(\mathrm{Naf}-112 / D T A^{+}\right)\right\rangle=(0.973 \pm 0.012)$, which hardly differentiate one from each other although they seem to indicate a slightly higher proton transport in the ILmodified membrane. Cation transport number values obtained in this paper hardly differ from those determined in [18] for a Nafion membrane and different electrolyte solutions.

3.5. Monitoring IL-Cation Inclusion Electrical Effects. As was already established in the previous sections, the $\mathrm{H}^{+} / \mathrm{DTA}^{+}$ exchange mechanism taking place when the Nafion-112 membrane was in contact with the IL solution causes changes in the membrane and the membrane solution interface. Time evolution of the impedance spectroscopy curves can give information on such changes. Figure 9 shows the impedance diagrams (Bode plots) obtained for the system electrode//ILsolution/Nafion-112/IL-solution//electrode at different time 


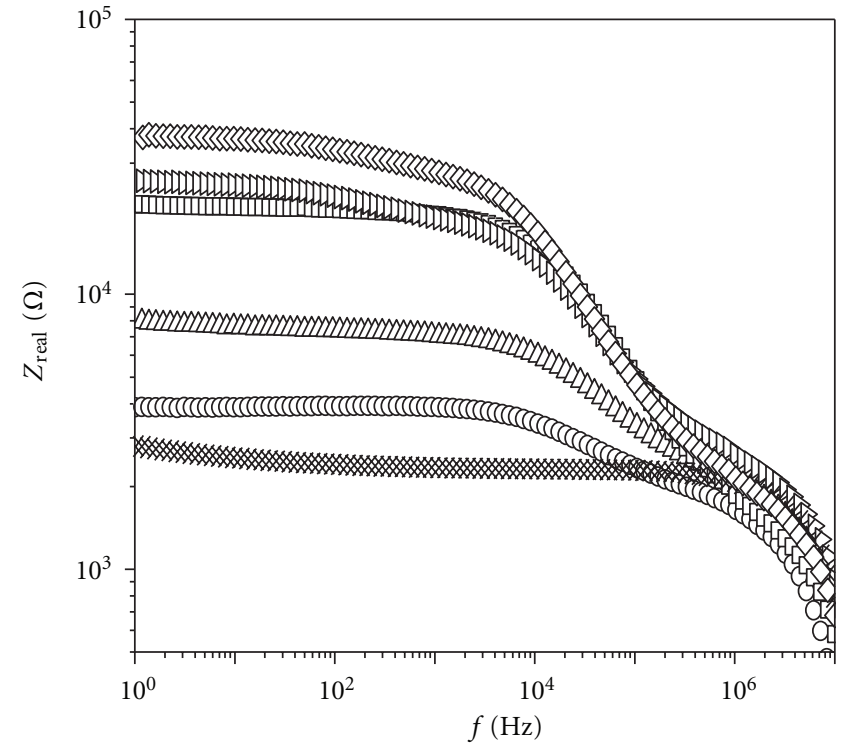

(a)

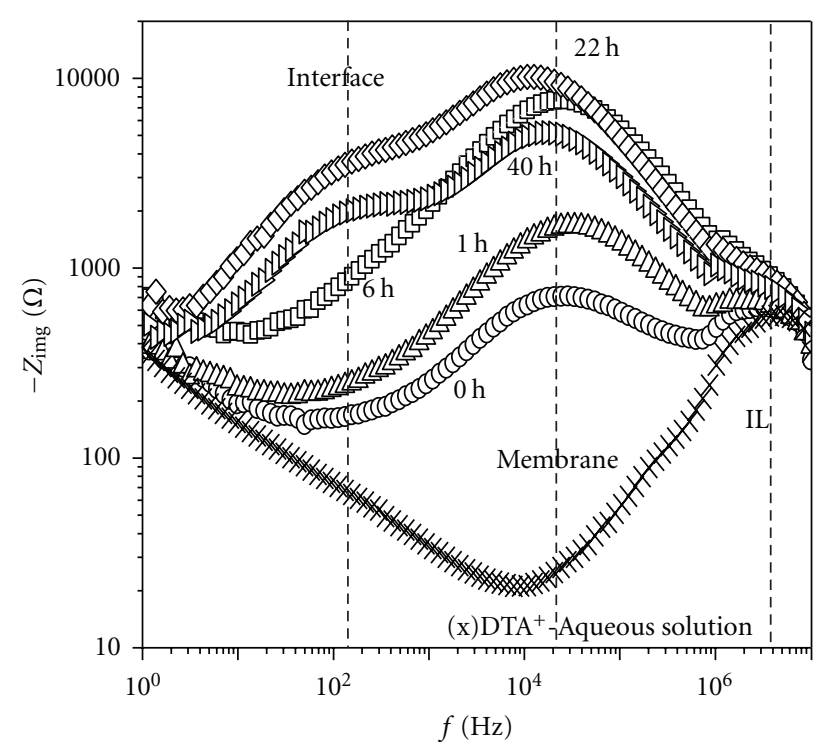

(b)

FIGURE 9: (a) Variation of the (a) real part of the impedance versus frequency and (b) imaginary part of the impedance versus frequency as a function of the Nafion-112 membrane contact time with the IL-solution. (o) $t=0,(\triangle) t=1 \mathrm{~h},(\square) t=6 \mathrm{~h},(\diamond) t=22 \mathrm{~h}$, and $(\nabla) t=40 \mathrm{~h}$. Impedance results for the IL-solution alone $(\times)$, this means without any membrane in the measuring cell are also drawn.

instances. For comparison, the impedance values measured with the IL solution (without any membrane placed in the cell) are also indicated in Figure 9. These results show the separate effect of DTA ${ }^{+}$inclusion (and $\mathrm{H}^{+}$lost) on both the real part of the impedance (related to the charge movement through the electrical resistance) and the imaginary part of the impedance (associated to charge storage by the capacitance). Figure 9 (a) shows the increase of $Z_{\text {real }}$ values for the membrane/IL-solution system with time, where there are higher values for $22 \mathrm{~h}$ than for $40 \mathrm{~h}$, but these results also include interfacial effects, which seem to be developed after $10 \mathrm{~h}$ of membrane/IL-aqueous solution contact. This point is more clearly observed in Figure 9(b), where different relaxations depending on the system and/or time period considered can be observed. As expected, the IL-solution only presents a relaxation at high frequencies $\left(f_{\max } \approx 3 \times\right.$ $10^{6} \mathrm{~Hz}$ ) since only free or "solution" charges are involved; however, the membrane/IL-solution system exhibits different behaviours depending on the time period which is associated to the exchange kinetic: (a) at the beginning of the exchange process the main effect observed corresponds to the increase in of membrane characteristic parameters (electrical resistance and capacitance) due to the replace of the small and high conductive proton $\left(\mathrm{H}^{+}\right)$by the wider and heavy $\mathrm{DTA}^{+}$-cation and two relaxation processes, one associated to the membrane $\left(f_{\max } \approx 10^{4} \mathrm{~Hz}\right)$ and another to the electrolyte solution placed between the electrodes and the membrane surfaces $\left(f_{\max } \approx 2-3 \times 10^{6} \mathrm{~Hz}\right)$ can be observed; (b) after some hours of membrane immersion in the IL-solution (around $10 \mathrm{~h}$ ) a structured profile seems to be developed at the membrane interface and then three different relaxation processes with maximum frequencies around $200 \mathrm{~Hz}$ (interface), $10^{4} \mathrm{~Hz}$ (membrane), and $2-3 \times 10^{6} \mathrm{~Hz}$ (electrolyte solution) are obtained. These latter curves are similar to those obtained with composite membranes (as those used for reverse osmosis or nanofiltration processes) in contact with common electrolytes solutions $(\mathrm{NaCl}$ or $\mathrm{KCl})$ and are associated to the typical double layer (dense-active layer/porous-support) structure of that kind of membranes $[36,37]$.

The fitting of the impedance data obtained for each time allows the estimation of the electrical resistance and capacitance associated to both bulk membrane and interface and its dependence with membrane immersion time in the ILsolution is shown in Figure 10. A significant increase in the membrane electrical resistance associated to the IL-cation incorporation (similar to that shown in Figure 1) can be observed in Figure 10, but an interfacial process seems to be developed after $6-8 \mathrm{~h}$, which practically corresponds to the time at which the proton/cation exchange mechanism for IL-cation incorporation reaches the plateau; this interfacial process is time decreasing probably due to counter-diffusion effect.

These results show the complexity of IL-cation incorporation into Nafion membranes associated to the kinetic of proton/IL-cation exchange as well as the possibility of using impedance spectroscopy technique to discriminate the effects associated to both the own membrane and the interface.

\section{Conclusions}

The modification of a typical cation-exchange polymeric membrane by inclusion of the IL-cation into the matrix structure by a proton/cation exchange mechanism and its effect on chemical, thermal, and charge transport was presented. Membrane thickness seems to affect equilibrium time 


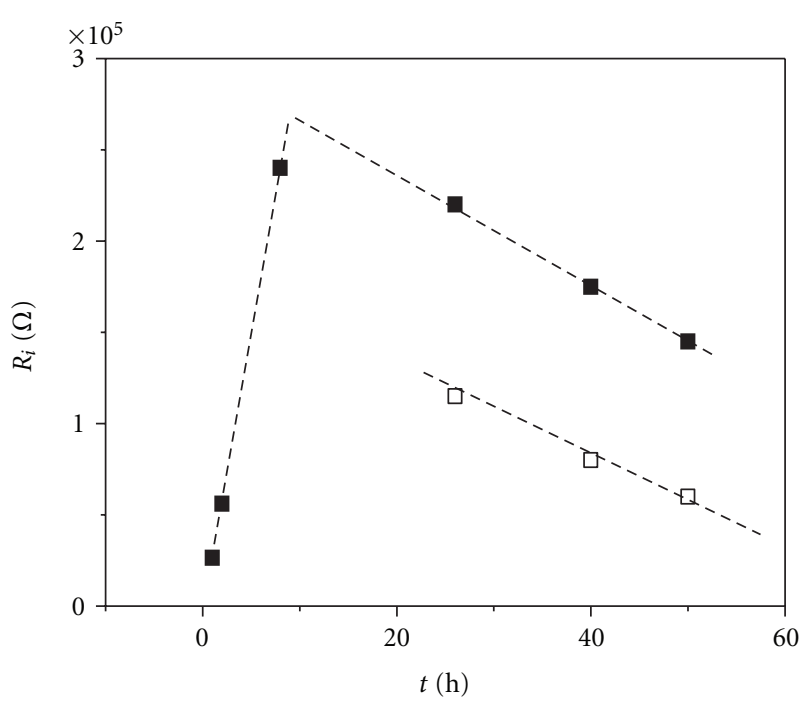

Figure 10: Time dependence of the electrical resistance of $(\mathbf{\square})$ bulk membrane, $(\square)$ interface.

but hardly modifies the incorporation degree at equilibrium, which presents an average value of $(60.5 \pm 0.5) \%$ for the Nafion-DTA ${ }^{+}$aqueous solution studied.

Electrical, thermal and surface characterizations of the studied systems were basically carried out by impedance spectroscopy, DSC, XPS, and contact angle measurements. $\mathrm{DTA}^{+}$incorporation seems to reduce the hydrophobic character of the original Nafion membranes and to increase their thermal stability. The effect of water in the electrical resistance of the modified samples was also shown, which is significant point for many electrochemical applications. Moreover, this work also presents the direct correlation between cation incorporation in the membrane and modifications in its electrical resistance but also associated interfacial effects.

The diversity of available ILs made it possible to choose that the use of IL-modified membranes' is more adequate for a specific application opening for a wide variety of applications, particularly those related to electrochemical systems.

\section{Acknowledgments}

V. Romero acknowledges the financial support to MICINN, Spain, through the FPU scholarship. The authors thank to Prof. J. Crespo, Prof. M. I. Coelhoso and Dr. A. Neves, Dpt. Chemical Engineering at the Universidade Nova de Lisboa for their supervision and help during cation-incorporation in membranes measurements, and to CICYT (Project CTQ2011-27770, FEDER funds) for financial support.

\section{References}

[1] T. Welton, "Room-temperature ionic liquids. solvents for synthesis and catalysis," Chemical Reviews, vol. 99, no. 8, pp. 2071-2083, 1999.

[2] F. van Rantwijk and R. A. Sheldon, "Biocatalysis in ionic liquids," Chemical Reviews, vol. 107, no. 6, pp. 2757-2785, 2007.
[3] Y. Hu and C. Xu, "Effect of the structures of ionic liquids on their physical-chemical properties and the phase behavior of the mixtures involving ionic liquids," Chemical Reviews, 2005.

[4] J. Ranke, S. Stolte, R. Störmann, J. Aming, and B. Jastorff, "Design of sustainable chemical products-the example of ionic liquids," Chemical Reviews, vol. 107, no. 6, pp. 21832206, 2007.

[5] M. Armand, F. Endres, D. R. MacFarlane, H. Ohno, and B. Scrosati, "Ionic-liquid materials for the electrochemical challenges of the future," Nature Materials, vol. 8, no. 8, pp. 621$629,2009$.

[6] L. J. Lozano, C. Godínez, A. P. de los Ríos, F. J. HernándezFernández, S. Sánchez-Segado, and F. J. Alguacil, "Recent advances in supported ionic liquid membrane technology," Journal of Membrane Science, vol. 376, no. 1-2, pp. 1-14, 2011.

[7] F. Endres, M. Armand, and D. R. MacFarlane, Eds., Electrodeposition from Ionic Liquids, Wiley, 2008.

[8] S. Rivera-Rubero and S. Baldelli, "Influence of water on the surface of hydrophilic and hydrophobic room-temperature ionic liquids," Journal of the American Chemical Society, vol. 126, no. 38, pp. 11788-11789, 2004.

[9] K. A. Mauritz and R. B. Moore, "State of understanding of Nafion,” Chemical Reviews, vol. 104, no. 10, pp. 4535-4585, 2004.

[10] J. S. Lee, N. D. Quan, J. M. Hwang et al., "Polymer electrolyte membranes for fuel cells," Journal of Industrial and Engineering Chemistry, vol. 12, no. 2, pp. 175-183, 2006.

[11] M. Saito, N. Arimura, K. Hayamizu, and T. Okada, "Mechanisms of ion and water transport in perfluorosulfonated ionomer membranes for fuel cells," Journal of Physical Chemistry B, vol. 108, no. 41, pp. 16064-16070, 2004.

[12] A. Siu, J. Schmeisser, and S. Holdcroft, "Effect of water on the low temperature conductivity of polymer electrolytes," Journal of Physical Chemistry B, vol. 110, no. 12, pp. 6072-6080, 2006.

[13] M. Doyle, S. K. Choi, and G. Proulx, "High-temperature proton conducting membranes based on perfluorinated ionomer membrane-ionic liquid composites," Journal of the Electrochemical Society, vol. 147, no. 1, pp. 34-37, 2000.

[14] C. Schmidt, T. Glück, and G. Schmidt-Naake, "Modification of Nafion membranes by impregnation with ionic liquids," Chemical Engineering and Technology, vol. 31, no. 1, pp. 1322, 2008.

[15] L. A. Neves, J. Benavente, I. M. Coelhoso, and J. G. Crespo, "Design and characterisation of Nafion membranes with incorporated ionic liquids cations," Journal of Membrane Science, vol. 347, no. 1-2, pp. 42-52, 2010.

[16] C. Iojoiu, M. Martinez, M. Hanna et al., "PILs-based Nafion membranes: a route to high-temperature PEFMCs dedicated to electric and hybrid vehicles," Polymers for Advanced Technologies, vol. 19, no. 10, pp. 1406-1414, 2008.

[17] N. P. Berezina, S. V. Timofeev, and N. A. Kononenko, "Effect of conditioning techniques of perfluorinated sulphocationic membranes on their hydrophylic and electrotransport properties," Journal of Membrane Science, vol. 209, no. 2, pp. 509-518, 2002.

[18] I. A. Stenina, P. Sistat, A. I. Rebrov, G. Pourcelly, and A. B. Yaroslavtsev, "Ion mobility in Nafion-117 membranes," Desalination, vol. 170, no. 1, pp. 49-57, 2004.

[19] V. S. Silva, B. Ruffmann, S. Vetter et al., "Mass transport of direct methanol fuel cell species in sulfonated poly(ether ether ketone) membranes," Electrochimica Acta, vol. 51, no. 18, pp. 3699-3706, 2006.

[20] M. Lavorgna, M. Gilbert, L. Mascia, G. Mensitieri, G. Scherillo, and G. Ercolano, "Hybridization of Nafion membranes with 
an acid functionalised polysiloxane: effect of morphology on water sorption and proton conductivity," Journal of Membrane Science, vol. 330, no. 1-2, pp. 214-226, 2009.

[21] E. Cho, J. S. Park, S. S. Sekhon et al., "A study on proton conductivity of composite membranes with various ionic liquids for high-temperature anhydrous fuel cells," Journal of the Electrochemical Society, vol. 156, no. 2, pp. B197-B202, 2009.

[22] J.-S. Park, M.-S. Shin, S. S. Sekhon, Y.-W. Choi, and T.-H. Yang, "Effect of annealing on Nafion recast membranes containing ionic liquids," Journal of the Korean Electrochemical Society, vol. 14, pp. 9-15, 2011.

[23] L. A. Neves, I. M. Coelhoso, and J. G. Crespo, "Methanol and gas crossover through modified Nafion membranes by incorporation of ionic liquid cations," Journal of Membrane Science, vol. 360, no. 1-2, pp. 363-370, 2010.

[24] R. Fortunato, C. A. M. Afonso, J. Benavente, E. RodriguezCastellón, and J. G. Crespo, "Stability of supported ionic liquid membranes as studied by X-ray photoelectron spectroscopy," Journal of Membrane Science, vol. 256, no. 1-2, pp. 216-223, 2005.

[25] F. J. Hernández-Fernández, A. P. de los Ríos, F. TomásAlonso, J. M. Palacios, and G. Víllora, "Preparation of supported ionic liquid membranes: influence of the ionic liquid immobilization method on their operational stability," Journal of Membrane Science, vol. 341, no. 1-2, pp. 172-177, 2009.

[26] R. Fortunato, L. C. Branco, C. A. M. Afonso, J. Benavente, and J. G. Crespo, "Electrical impedance spectroscopy characterisation of supported ionic liquid membranes," Journal of Membrane Science, vol. 270, no. 1-2, pp. 42-49, 2006.

[27] J. D. Ramos, C. Milano, V. Romero et al., "Water effect on physical-chemical and elastic parameters for a dense cellulose regenerated membrane: transport of different aqueous electrolyte solutions," Journal of Membrane Science, vol. 352, no. 1-2, pp. 153-159, 2010.

[28] Celula Laura Ceramics International and J. Benavente, "Electrical characterization of membranes," in Monitoring and Visualizing Membrane-Based Process, C. Güell, M. Ferrando, and F. López, Eds., Wiley, 2009.

[29] M. J. Ariza, J. Benavente, and E. Rodríguez-Castellón, Handbook of Membranes: Properties, Performance and Applications, Nova Science Publishers, New York, NY, USA, 2009.

[30] National Institute of Standard and Technology (NIST), X-Ray Data Base, Gaithersburg, Md, USA, 1997.

[31] V. Di Noto, E. Negro, J. Y. Sanchez, and C. Lojoiu, "Structurerelaxation interplay of a new nanostructured membrane based on tetraethylammonium trifluoromethanesulfonate ionic liquid and neutralized nation 117 for high-temperature fuel cells," Journal of the American Chemical Society, vol. 132, no. 7, pp. 2183-2195, 2010.

[32] J. R. Macdonalds, Impedance Spectroscopy, Wiley, New York, NY, USA, 1987.

[33] J. Benavente, "Use of impedance spectroscopy for characterization of membranes and the effect of different modifications," in Membrane Modification: Technology and Applications, N. Hilal, M. Khayet, and Ch. J. Wright, Eds., CRC Press, 2012.

[34] J. Benavente, "Electrochemical impedance spectroscopy as a tool for characterization of membranes in contact with electrolyte solutions in Surface Electrical Phenomena," in Membranes and Microchannels, A. Szymczyk, Ed., Transworld Reserach Network, 2008.

[35] N. Lakshminarayanaiah, Transport Phenomena in Membranes, Academic Press, New York, NY, USA, 1969.
[36] A. Cañas, M. J. Ariza, and J. Benavente, "Characterization of active and porous sublayers of a composite reverse osmosis membrane by impedance spectroscopy, streaming and membrane potentials, salt diffusion and X-ray photoelectron spectroscopy measurements," Journal of Membrane Science, vol. 183, no. 1, pp. 135-146, 2001.

[37] C. Torras, X. Zhang, R. García-Valls, and J. Benavente, "Morphological, chemical surface and electrical characterizations of lignosulfonate-modified membranes," Journal of Membrane Science, vol. 297, no. 1-2, pp. 130-140, 2007. 


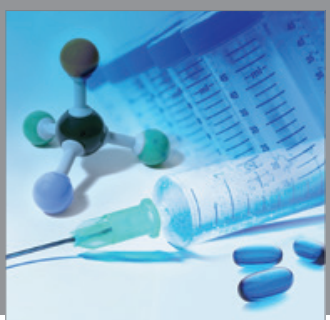

International Journal of

Medicinal Chemistry

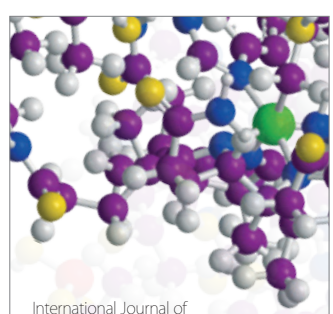

Carbohydrate Chemistry

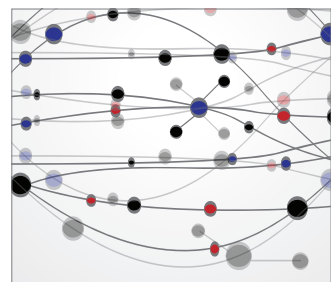

The Scientific World Journal
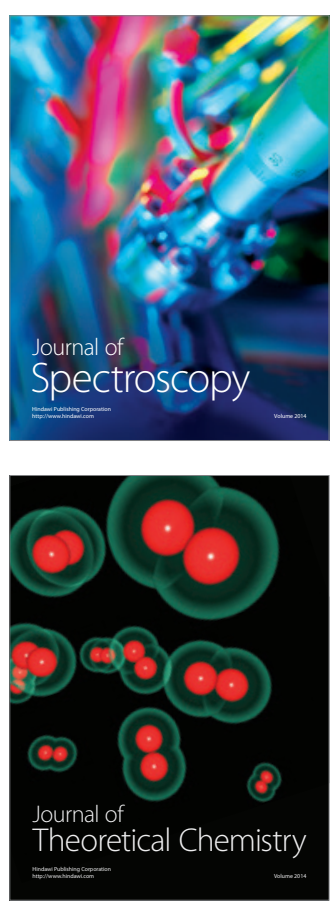
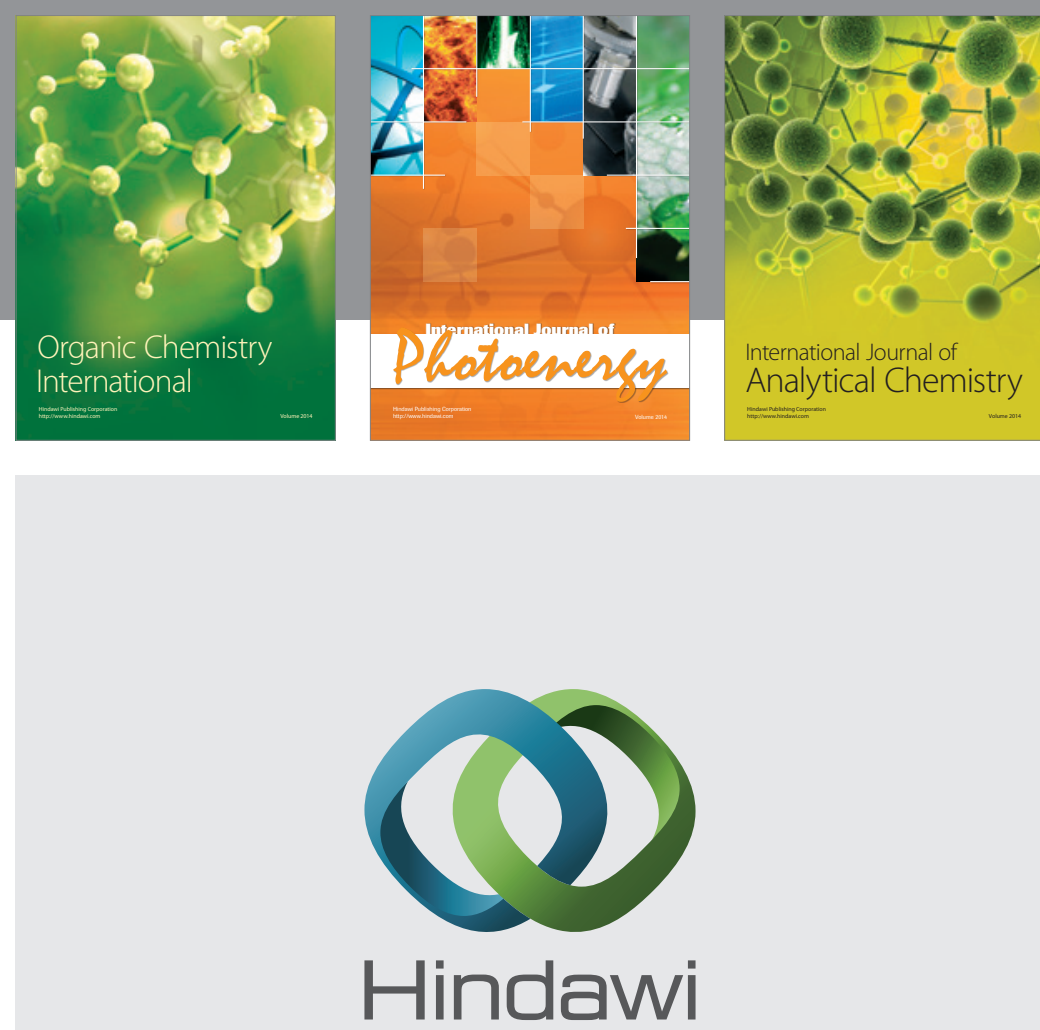

Submit your manuscripts at

http://www.hindawi.com
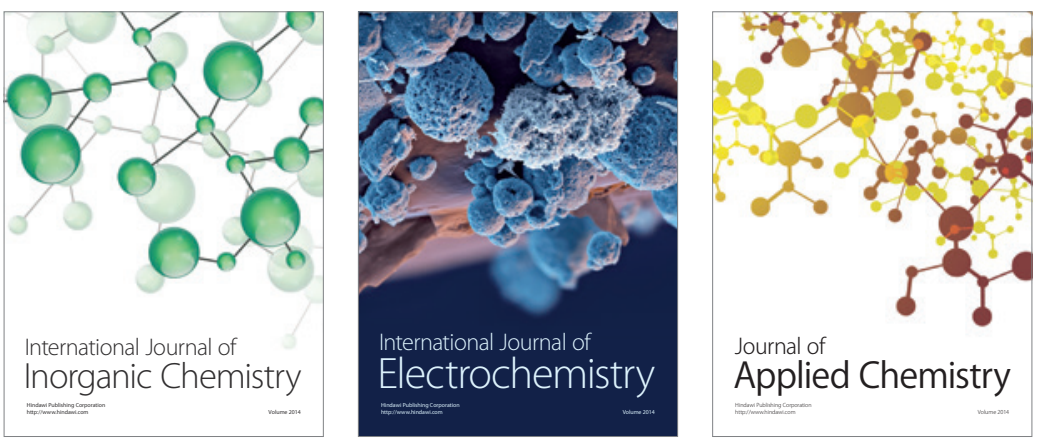

Journal of

Applied Chemistry
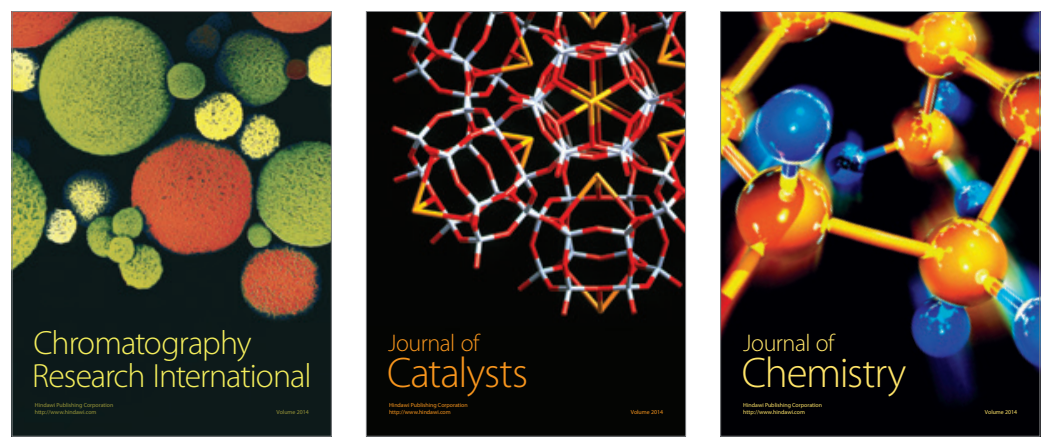
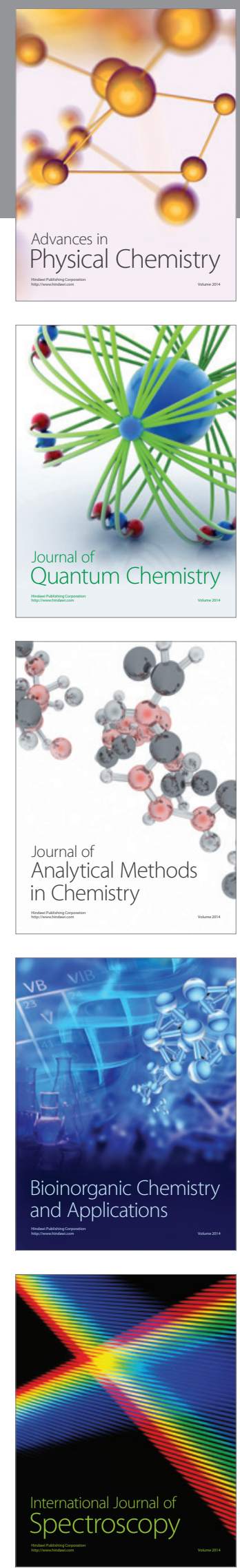